\title{
LA FARMACIA ANDALUSÍ: GRANDES INNOVACIONES PARA UNA PROFESIÓN
}

Esteban MORENO TORAL*

En la actualidad, el farmacéutico desarrolla su profesión como especialista del medicamento ofreciendo su asesoramiento y vigilancia con respecto al paciente, tanto a nivel comunitario, hospitalario, o clínico. La educación para la salud del ciudadano tiene en el farmacéutico una parte importante de la cadena, provista tanto de aspectos científicos como humanos. El nuevo concepto de atención farmacéutica marca la tendencia de la profesión de presente y del fututo. Además el farmacéutico participa de otros sectores de gran importancia en la salud como son el de la nutrición y dietética, el de las ciencias ambientales, los análisis clínicos, los establecimientos parafanmacéuticos, ,...

Gran parte de este status tienen su origen en las importantes aportaciones e innovaciones, así como el nuevo sentido que el pueblo árabe y más concretamente el andalusí dio a las ciencias farmacéuticas. El objetivo de este artículo es dar a conocer estas aportaciones, lo que puede servimos para comprender la profesión del hoy y del mañana. Sus problemas, sus innovaciones y sus limitaciones son una fuente importante del conocimiento de la profesión. Dicen que quien conoce la historia tiene la posibilidad de conocer mejor su presente. Y es que, la historia se repite con demasiada frecuencia, reiterando el hombre en cada generación los mismos planteamientos a sus dudas, y a sus problemas.

\section{CONTEXTO HISTÓRICO}

La toma de Granada por los Reyes Católicos, el 2 de enero de 1492, culmina un período de la Historia de España, conocido como período islámico o árabe, o simplemente como Historia de Al-Andalus. El derrotado, era Boabdil, último rey nazarí de Granada, apodado por los cristianos «El Rey Chico». La leyenda se ha

* Profesor Titular del Departamento de Farmacia y Tecnología Farmacéutica. Universidad de Sevilla. 
apoderado de este personaje, ya que cuando éste dirigió una última mirada a Granada antes de partir hacia el destierro, se refiere un hecho muy popular y recordado: el rey chico comenzó a llorar y su madre, Aisa al-Hurra, le increpó con estas palabras: Llora, llora como mujer lo que no supistes defender como hombre.

La historia de Al-Andalus había comenzado 781 años atrás, concretamente en el 711 con la victoria de las tropas de Tariq sobre las del rey de Toledo, Don Rodrigo, en la batalla de Guadalete. Al-Andalus fue el nombre que en el medievo los escritores árabes dieron a la España musulmana, y cuya extensión fue disminuyendo con los siglos, en el VIII prácticamente ocupaba toda la península, en el $\mathrm{X}$ el sur peninsular y en el XV tan sólo el reino de Granada ${ }^{1}$.

La impronta que el pueblo árabe nos ha dejado durante sus ocho siglos de permanencia en nuestra tierra ha inundado las distintas ramas del conocimiento, la cultura, la economía, la sociedad, las humanidades y la ciencia ${ }^{2}$. No obstante, hay que reseñar que el llamado legado andalusí, es fruto y consecuencia de la cooperación de comunidades bien diferenciadas: la islámica, la cristiana y la judía; unidas por el común anhelo de saber, conocer y realizar nuevas aportaciones.

\section{EL LEGADO ANDALUSÍ Y LAS CIENCIAS DE LA SALUD}

Nuestra sociedad está inundada de circunstancias que han sido transmitidas gracias al legado andalusí. Los diferentes grupos étnicos: yemeníes, qaysíes, bereberes, almorávides, almohades o nazaríes dejaron su impronta a lo largo de los siglos. En lo arquitectónico numerosos edificios que embellecen muchos pueblos y ciudades del sur peninsular. Por mencionar algunos: La Alhambra de Granada, La Mezquita Cordobesa o la Giralda de Sevilla. También destacar la importancia del agua en su entorno, en el campo como contenido de las canalizaciones y en la urbe como componente alegre y fresco con su borboteo en fuentes, baños, plazas y viviendas. Referente a la cultura y la ciencia, hay que destacar el gran auge y brillantez que ésta adquirió, en especial en la Córdoba califal, tanto por el

1. Sobre la Historia Política de Al-Andalus pueden consultarse: CHALMETA, P. (1989): «Al-Andalus» (pp. 9-114) en Volumen III de la Historia de España dirigida por Antonio Domínguez Ortiz; LEVÍ-PROVENCAL, E. (1950-56): Histoire de l'Espagne musulmane. París; LOPEZ DE COCA, J.E. (1982): «Los Reinos de Taifas y las Dinastías Bereberes» (pp. 13-94), en Volumen II de La Historia de Andalucía dirigida por Antonio Domínguez Ortiz; MEDINA MOLERA, A. (1980-81): Historia de Andalucía, Sevilla; SANCHEZ MARTINEZ, M. (1982): «Apogeo y crisis deI Estado Cordobés», (pp.189-352) en Volumen I de La Historia de Andalućáadirigida por Antonio Domínguez Ortiz; VIGUERA MOLINS, M.J. (1992): Los Reinos de Taifas y las Invasiones Magrebies.

2. Respecto a aspectos sociales, culturales, y económicos, resulta útil: CUENCA TORIBIO, J.M. (1982): Andalucía Historia de un pueblo (... a C.-1982); Capítulo V, (pp. 173-280), Madrid; CHARNAY, J.P. (1967): LÁmbivalence dans la culture arabe, París; MARIN, M. (1992): Individuo y Sociedad en Al-Andalus, Madrid; TORRES BALBAS, L. (1971): Ciudades hispano-musulmanas, Ministerio de Asuntos Exteriores, Instituto Hispano Arabe de Cultura, Madrid, 2 Vols; VÁZQUEZ MEDEL, M.A. (1994): La construcción cultural de Al-Andalus, Sevilla. 
número como por la gran calidad de sus aportaciones. En un principio fue muy humilde, pero a partir del establecimiento del Califato cordobés con Abderrahman III en el siglo $\mathrm{X}$, se produce el mayor florecimiento como potencia tanto política como científica en todo el mundo occidental.

La vinculación con el Oriente Islámico, a partir del siglo XI utilizando a los eruditos que realizaban viajes de estudios como canales de comunicación, supondría el auge y desarrollo de disciplinas como la Astronomía, la Ingeniería, la Medicina, la Botánica y la Farmacología ${ }^{3}$. Con este excepcional substrato, no resulta extraño que se dieran las circunstancias idóneas para la aparición de una pléyade de grandes figuras, cuyo legado a la humanidad, en todas las ramas del saber, ha sido de gran valor.

La ciencia árabe en general, estará caracterizada por dos notas particulares: la primera, el gran poder de asimilación de los conocimientos, tanto de las civilizaciones anteriores a ellos como de los pueblos con los que entra en contacto durante la expansión del Islam; y la segunda, el carácter enciclopédico de la gran mayoría de las obras de sabios y científicos árabes.

Podemos afirmar por tanto que la ciencia andalusí de los siglos VIII y IX se encuentra en período de formación, en la que coexisten aspectos científicos, empíricos y mágicos. Todo este caldo de cultivo del saber, no eclosionaría en AlAndalus hasta bien entrado el siglo $\mathrm{X}$, casi un siglo más tarde que en Oriente, alcanzando gran madurez y producción. Se produce durante el reinado de Abderrahman III, con una Córdoba constituida como gran centro del mundo científico y cultural.

En el ámbito de la farmacología un hecho fue determinante en su eclosión: el regalo que hacia el año 948, el emperador de Constantinopla, Constantino VII, erudito y aficionado al mundo de las letras y las artes, hizo a Abderrahman III de un ejemplar en griego de la Materia Médica de Dioscórides y su posterior traducción del texto por el monje llamado Nicolás, el cual llegó a formar a su alrededor un gran círculo de eruditos, entre ellos el judío Hasdãy ben Saprūt. El texto influiría de manera decisiva en gran número de escritos árabes ${ }^{4}$.

3. Dos de las obras básicas y más recientes para el estudio de la Ciencia en Al-Andalus son la de: SAMSO, J. (1992): Las Ciencias de los Antiguos en Al-Andalus, Madrid; y GARCIA SANCHEZ, E. (1992): Ciencias de la Naturaleza en Al-Andalus. Textos y Estudios, Granada (1990, Vol. I) y Madrid (1992, Vol. II). Una amplia bibliografia puede encontrarse en: LÓPEZ PIÑERO, J.M.; PESET REIG, M.; GARCÍA BALLESTER, L. (1973): Bibliografía Histórica sobre la Cienciay la Técnica en España, 2 volúmenes, Valencia-Granada. Son de útil consulta: SEGURA PÉREZ, F.; LOZANO CÁMARA, I. (1992): Ciencias de la Naturaleza en Al-Andalus. Serie Bibliografica, Madrid, 1992; MILLAS VALLICROSA, J.M. (1987): Estudios sobre Historia de la Ciencia Española, Madrid; MILLAS VALLICROSA, J.M. (1991): Nuevos Estudios sobre Historia de la Ciencia Española, Madrid; VERNET, J. (1976): Historia de la Ciencia Española, Valencia; VERNET, J. (1986): La Ciencia en Al-Andalus, Sevilla. Resulta muy ilustrativa la obra editada en 1992 por el Museo Arqueológico Nacional de Madrid titulada El Legado Científico Andalusí.

4. Una de las obras más completas en lengua modema, sobre la transmisión e influencia de la Materia Médica de Dioscórides, en el medievo árabe y latino es: DUBLER, C.E. (19531957): La «Materia Médica» de Dioscórides, 5 Volúmenes, Barcelona. También es de obligado examen: HAMARNEH, S. (1977): «Arabic Manuscripts ofthe 
Precisamente será la Farmacología junto a la Botánica las disciplinas que harár de puente entre las ciencia médica y farmacéutica, ya que si bien permanecen aúr unidas en muchos aspectos, comenzarán a adquirir nuevas identidades particulares ${ }^{5}$

El médico andalusí recibía un aprendizaje combinando lecciones teóricas jun. to a la enseñanza práctica, desarrollada generalmente en visitas a enfermos, tantc en sus casas como en hospitales. El alumno era normalmente una persona de edac madura, ya que para alcanzar el status de médico se requería haber alcanzado previamente un entendimiento global de la naturaleza, y un buen sentido común. Las enseñanzas eran desarrolladas con frecuentes diálogos entre el hakim y sus discípulos, que en ocasiones se tornaban en polémicas. Completaba su formaciór. humanística con elementos científicos de astrología, agronomía, y matemáticas. Culminaba su educación con amplios contenidos de botánica, farmacología, terapéutica, y cirugía. Algunos textos didácticos presentan características muy peculiares. Baste citar libros redactados en verso, que los alumnos debían memorizar. o aquellos otros que utilizaban el juego de preguntas y respuestas que trataban cuestiones relativas a la enfermedad'.

El lugar de enseñanza recibía el nombre de madrasa. En un principio se ubicaba en el interior de la mezquita, donde en una sala o patio se situaba el maestro con los discípulos alrededor en semicírculo, sentados sobre esteras. Con los años, y especialmente a partir del siglo XI, se establecieron madrasas en sitios distintos a la mezquita, transformándose en academias formales con bibliotecas, instalaciones hospitalarias, farmacias, etc... El centro de enseñanza ubicado en el hospital recibió el nombre de bīmāristān ${ }^{7}$.

National Library of Medicine», Washington, D.C., Journal for the History of Arabic Science, Number 1, Vol. 1, pp. 72-107; LECLERC, L. (1867): «De la traduction arabe de Dioscorides et de traductions arabes en général», JournalAsiatique, óe serie. IX, pp. 5-38; MEYERHOF, M. (1933): «Die Materia Medica des Dioskurides bei den Araben, Quellen und Studien zur Geschichte der Naturwissenchaften und der Medizin», III, 4, pp. 72-84; SADEK, M.M. (1983): The Arabic Materia Medica of Dioscorides, Quebec; ULLMANN, M. (1978): Islamic Medicine, Edinburgh University Press; pp. 7-40.

5. En general resultan de gran utilidad para el estudio de Ias ciencias médicofarmacéuticas en el Islam, algunos de los trabajos de Sami K. Hamarneh. Entre ellos: HAMARNEH, S.M. (1964): Bibliography on Medicine and Pharmacy in Medieval Islam, Stuttgart, Wissenchaftliche Verlasgesellscheft.; HANtARNEH, S.M. (1983): Health Sciences en early Islam: collectedpapers, San Antonio; HAMARNEH, S.M. (1987): Index of Arabic Manuscripts on Medicine and Pharmacy at the National Library of Cairo, El Cairo. Igualmente, entre los textos más completos: CASTIGLIONI, A. (1947): «Arabian Medicine» en A History of medicine, New York, pp. 258-287; ROSENTHAL, F. (1975): The clasical heritage in Islam, London; ULMANN, M. (1978): Islamic Medicine, Edinburgh.

6. Sobre las ciencias médicas; AHMAIt S. (1965): En souvenir de la Medecine Arabe. Quelques uns de sesgrands noms. Tunez.; LECLERC, L. (1971): Histoire de la medicine arabe. Paris.; ROSENTHAL, F. (Jr.). (1990): Science and Medicine in Islam: a collection of essays. Brookfield, VT. Sobre el ejercicio médico: HAMARNEH, S. (1973): «Some aspects of medical practice and institutions in Medieval Islam», Episteme. Vol. 7, pp. $15-3$ 1; ROSENTHAL, F. (1978): «The Physician in Medieval Muslim Society», Bulletin of the History of Medicine, Vol. 52, pp. 475-491. Sobre la Deontología Médica: LEVEY, M. (1966): "Medical Deontology in Nith Century Islam», Journal of History of Medicine. Vol. 21, pp. 358-373; SCHIPPERGES, H. (1981).: «Sobre la postura ética del médico» en Historia Universal de la Medicina, vol. 3, pp. 74-77; DONALDSON, M. (1953): Studies in Muslim Ethics, London.

7. Sobre los hospitales en el Islam: HAMARNEH, S. (1962): «Development of Hospitals in Islam», Journal of History Medicine, Vol. 17, pp. 366-384; en particular sobre los hospitales en Al-Andalus: INAMUDDIN, S.M. 
Entre las ciencias farmacéuticas hay que destacar en especial a la terapéutica, la cual entendían que se desarrollaba en tres fases: la dietética, la farmacología y la cirugía.

La Dietética en la terapéutica árabe constituye el primer peldaño al que se acude para devolver el cuerpo a su estado de salud. Solamente cuando el desequilibrio que padece el enfermo no puede ser restaurado por esta vía, se acude al tratamiento farmacológico y en última instancia al quirúrgico. Un tratado de Hunayn aborda la importancia de la conservación de una buena dentadura en el proceso de una adecuada alimentación. Señala algunos consejos para una buena dieta: debe permitirse que los alimentos tengan una adecuada digestión en el estómago, debe inducirse el vómito cuando el paciente tiene hiperacidez, tomar gomas de mascar para eliminar restos de comida en los dientes, comer frutas ácidas, tomar bebidas muy frías o comer hielo después de comidas calientes

En cuanto a la Farmacología ${ }^{8}$, hay que tener presente que los árabes definían medicamento como aquella sustancia que ejercía una influencia sobre el cuerpo humano o animal, y establecían dos clases: los simples (adwiyya mufrada) y los compuestos (adwiyya murakkaba o aqrābādīn). La terapéutica árabe se basaba en el principio alopático contraria contrariis curantur. Por tanto, la farmacología debe elegir aquel medicamento que fuese de igual fuerza pero opuesto a la cualidad que alteraba la complexión. Las teorías de Galeno referentes a los cuatro grados de los medicamentos fueron ampliamente seguidas, aunque se incluyeron nuevas contribuciones como la del autor al-Kindi.

La enseñanza de la farmacología en el mundo árabe ideó un curioso método, los «taqwim» o "tableros de ajedrez», grandes mosaicos en cuyos laterales se situaban los cuatro elementos con sus cuatro cualidades, opuestos a los cuatro grados de acción.

Contemplaban medicamentos de varios grados: primarios, cuando producen calentamiento, enfriamiento, desecación o humidificación; secundarios los que causan adormecimiento, combustión,...; terciarios, los que originan acciones concretas en un órgano determinado. Todo esto había de tenerse en cuenta a la hora de establecer la llamada indicación terapéutica.

(1978): «Māristān (Hospitals) in Medieval Spain», Islamic Studies, Vol 17, pp. 45-55.; GIRÓN IRUESTE, F. (1978): «En tomo al Maristan (Hospital Árabe) de Granada», Asclepio, Vol XXX, pp. 223-231.

8. Sobre el estudio de la Farmacología: DIETRICH, A. (1980): «Islanic Sciences and the Medieval West: pharmacology», en Islam and the Medieval West. Albany,; MEYERHOF, M. (1935): «Equisse d'histoire de la pharmacologie et botanique chez les musulmans d'Espagne», Al-Andalus, Vol. 3, pp. 1-41; HAMARNEH, S.M.; SONNEDECKER, G. (1963): A Pharmaceutical view of Abulcasis al-Zahrāwi in Moorish Spain with special reference to he 'Ádhān" Leiden; HAMARNEH, S.M. (1969): "Origins of Arabic Drug and Diet Therapy». Physis, Vol. 11, 267-286; HAMARNEH, S.M. (1970): «Sources and Development of Arabic Medical Therapy and Pharmacology», Sudhoff s Archiv. ZeitschriftFur Wissenchafts-Geschichte, Vol. 54, pp. 30-48; HAMARNEH, S.M. (1972): «Development of Arabic Medical Therapy in the Tenth Century», Journal of the History of Medicine, Vol. 27, pp. 65-79; TSCHIRCH, A. (1910): Handbuch der Pharmacognosie, Leipzig, Vol. I. 
Por otro lado, existieron unos textos árabes que recogían específicamente la composición de los medicamentos, que recibían el nombre de Aqrabadin. Serían los precursores de Antidotarios y Farmacopeas. Fueron textos de gran utilidad en el ejercicio de la profesión farmacéutica. El primer Aqrabadin de Al-Andalus, está escrito por 'Abd Rabbih, a mediados del siglo X.

Por último, la Cirugía era entendida como la última fase de la terapia, ya que sólo debía utilizarse cuando la dietética y la farmacología habían agotado sus posibilidades. El auge que experimentó durante el medievo árabe fue de gran magnitud, hasta el punto que la Europa latina a partir del siglo XIIl se hallará bajo su influencia. La Cirugía ${ }^{9}$ se encuentra lógicamente vinculada a la Anatomía, y al prejuicio religioso que consideraba impuro la disección del cuerpo humano. Los avances quirúrgicos en campos como la obstetricia y la oftalmología fueron espectaculares respecto a la heredad clásica. La aparición de numerosos instrumentos obstétricos y de ginecología revolucionaron las prácticas quirúrgicas. Aparecen, por vez primera unas tenazas con cuchara plana en forma circular, para la extracción de la cabeza en el parto. Consta además, que ya existían comadronas bien adiestradas. La oftalmología también experimentó un gran auge gracias al gran número de textos y a la práctica frecuente de estas operaciones en los hospitales: idearon un nuevo método para la operación de cataratas mediante succión con un trocar metálico.

Utilizarían, dentro de la práctica quirúrgica, nuevos métodos de cauterización, en abscesos, bubones, hemorroides, gangrena, etc...; los cuales seguirían vigentes hasta la Edad Modema. Se producen importantes avances en el conocimiento de la coagulación de la sangre, de la ligadura de arterias y en la compresión. Para paliar el dolor, utilizaban además del frío, unas esponjas somníferas impregnadas con opio, mandrágora e hiosciamo. El arsenal de medicamentos utilizado en la cirugía es bastante amplio. Como sedantes emplearon compresas húmedas de infusiones de manzanilla, anís y de aceite de rosas.

\section{LOS GRANDES FARMACÓLOGOS ANDALUSIES}

Al-Andalus fue cuna de un gran número de farmacólogos ${ }^{10}$. A continuación vamos a exponer la vida y obra de 4 de ellos, quienes contribuyeron espectacularmente al avance de las ciencias de la salud.

9. Sobre Cirugía: AL-'IMRANI, A. (1987): «Andalusian medicine: Theory and practice», Boletín de la Asociación Española de orientalistas, Vol. 23, pp. 379-385.

10. De gran utilidad en la elaboración de este capítulo son las obras: ARJONA CASTRO, A. (1989): Introducción a la Medicina arábigo andaluza (siglos VIII-XV), Córdoba, LECLERC, L. (1876): «Espagne et Magreb», en Histoire de la médecine arabe, París, pp. 240-253; HAMARNEH, S .M. (1964): Bibliography on Medicine and Pharmacy in Medieval Islam. Stuttgart, Wissenchaftliche VerlasgeselIscheft; STRAYER, J.R. (1985): Dictionary of The Middle Ages, Vol. 6, New York; VILLANUEVA, C, (1958): «La Farmacia árabe y su ambiente 
ABULCASIS ${ }^{11}$. Conocido también como al-Zaharāwī por ser natural de Madinat al-Zahará. Estudió en las excelentes escuelas de la ciudad y pronto se convirtió en un médicofarmacéutico-cirujano superior al resto de sus compañeros.

La obra más importante de Abulcasis, fue el famoso Tasrif, en la que intentó recopilar todos los conocimientos médicos de su tiempo. Constaba la enciclopedia médica de 30 secciones diferentes. La parte farmacológica circuló con el título de Liber Servitoris. En el primer tratado comienza exponiendo sus objetivos y los medios para conseguir condensar, en una enciclopedia, lo más útil en la práctica médico-farmacéutica para los estudiantes. Justifica el uso de medicamentos compuestos que él mismo elaboraba en la mayoría de las recetas prescritas.

La mención de diversos minerales y piedras preciosas sugiere cierta aproximación a la quimioterapia. Los tratados del diez al dieciocho los dedica el autor aI estudio de un gran número de formas farmacéuticas, tales como las trypheras, jarabes y robs, nueces catárticas, electuarios, decocciones, conservas, y polvos.

Es uno de los textos más importantes de la literatura árabe, con un contenido farmacéutico de gran riqueza, variedad y amplitud, y se extiende a todas las facetas que hay que conocer acerca del medicamento, como la identificación y recolección de drogas, pasando por los procedimientos de conservación y las técnicas de elaboración de las diversas formas farmacéuticas. La discusión de la naturaleza, propiedades, fuerza y grado de la acción farmacológica de las drogas es una preocupación constante en la obra, así como la determinación de sus usos terapéuticos.

AVENZOAR $^{12}$. Su nombre era Abū Marwān'Abd al-Malik ibn Zuhr. Nació en Peñaflor en el año 1092 y murió en Sevilla en el 1162, siendo enterrado en la Puerta de la Victoria. Ha sido uno de los sabios más famosos del Islam, el más célebre, quizá, de la escuela arábigoespañola, y tan famoso, o más que su discípulo Averroes, al que mimó como hijo espiritual, inculcándole la ciencia, tras dedicarle su más famosa obra, que fue El Taysīr.

Sigue un método empírico para describir las enfermedades, apoya sus observaciones en la experiencia. Le fueron familiares las autopsias, a despecho de preceptos religiosos, y fue un gran clínico, inventor del cateterismo esofágico, de los

históricon, Miscelánea de Estudios Árabesy Hebraicos, Vol. VII, pp. 2983; VILLANUEVA, C, (1960); «La Farnacia árabe y su ambiente histórico", Miscelónea de Estudios Árabes y Hebraicos, Vol. IX, pp. 167- 179. HAMAIRNEH, S .M. (1975): Catalogue of Arabic Manuscripts on Medicine and Pharmacy at the British Library. El Cairo, FERNANDEZ, F. (1936): La medicina árabe en España, Barcelona.

11. Sobre Abulcasis: HAMARNEH, S.M.; SONNEDECKER, G. (1963): A Pharmaceutical view of Abulcasis al-Zahrāwi in Moorish Spain with special reference to he "Ádhän». Leiden; ARVIDE CAMBRA, M.L. (1992): «El manuscrito árabe 5772 de la Biblioteca Nacional de París sobre el Kitāb Al-Tasrīf de Al-Zabrāwī», en La Ciencia en la España Medieval: musulmanes, judios y cristianos. Granada, pp. 31 -37.

12. Sobre Avenzoar: PEÑA, C; GIRÓN, F. (1977): «`Aspectos inéditos en la obra médica de Avenzoar: el prólogo del Kitāb Al-Taysīr. Edición, traducción y comentarios». Miscelánea de Estudios Arabes y Hebraicos. Vol. 26, pp. $103-116$. 
enemas alimenticios, y de una serie de hallazgos y descubrimientos que lo elevan a un lugar de primera fila entre las figuras del Islam andalusí.

Escribió el ya mencionado y célebre Taysìr, excelente manual de terapéutica que recoge diferentes fórmulas de medicamentos compuestos y explica el modo de componer jarabes, electuarios y unguentos. En su epitafio podemos leer:

La tierra de la tumba sobre mis mejillas
como si no hubiera caminado
un día por encima de ella.
La medicina de los hombres
guarda de la muerte
pero yo la practiqué un día
y aqui estoy ahora en sus manos.

AVERROES ${ }^{13}$. Abū al-Wal̄̄id Muhammad ben Ahmad ibn Rush. Posiblemente el andalusí que mayor influjo ha ejercido a lo largo de la historia del pensamiento humano. Se distinguió como médico y como filósofo. En su faceta como pensador jugó para el Islam un papel análogo al de Maimónides con respecto al judaísmo o al de Santo Tomás de Aquino en el mundo cristiano; y como médico colmó el cenit de esta ciencia en la hispanidad islámica, quizás por su brillante personalidad más que por las teorías curativas que sustentaba.

Heredero de su padre en la magistratura cordobesa, fue después gobernador de Sevilla y de Marruecos y, al fırí, de toda la Mauritania, cuyas leyes y jurisprudencia reformó, organizando los tribunales y la administración. Leclerc lo califica como «El hombre más grande de toda la España musulmana», y esto, que resulta evidente si nos atenemos a sus trabajos fílosóficos, es un poco exagerado en lo que a medicina se refiere.

Como médico, su obra más conocida es la enciclopedia titulada: Libro de las generalidades en medicina, conocida por los latinos como Colliget. La originalidad de su obra médica, reside especialmente en el espíritu de observación y consideración estática de la anatomía, y en haber roto con la tradición galénica.

Averroes murió en la ciudad de Marrakūš, capital del imperio almohade, en el 1198 a los setenta y dos años de edad. Su cadáver llegó a Córdoba colocado en una bestia de carga, sirviendo de contrapeso al ataúd, sus obras en el costado opuesto de la acémila.

MAIMÓNIDES ${ }^{14}$. Moseh ben Maimon, fue el más grande de todos los judíos peninsulares. Fue médico de Saladino, negándose a serlo de Ricardo Corazón de León, por razones de incompatibilidad religiosa.

13. Sobre Averroes: TORRE. E. (1974): Averroes y la ciencia médica La doctrina anatomofuncional del "Colliget", Madrid; MARTINEZ LORCA, A. y otros (1993): AlAndalus. TextosyEstudios,Madrid.

14. Sobre Maimónides: ROSNER, F. (1984): Medicine in the Mishneh Torah of Maimonides. New York; BARUCH, J.Z. (1969): «Maimonides as a Physician», Janus, Vol. 56, pp. 248-258. 
Maimónides nos dejó interesantes escritos en materia médico-farmacéutica. No creyó nunca en las fuerzas sobrenaturales como causantes de la enfermedad. Sostuvo, que las dolencias se deben a causas naturales, y que con medios de la naturaleza debían ser combatidas. Luchó contra el obscurantismo y la magia, ciencias muy difundidas en aquella época.

El Libro de los aforismos relacionados con la medicina, conocido por los hebreos como Pirqe Moseh, lo componen una serie de aforismos y verdades extractadas de las más famosas obras de Galeno, a las que añadió el comentarista observaciones propias.

\section{LOS PROFESIONALES DE LA FARMACIA EN AL-ANDALUS}

Los árabes fueron receptores de las ciencias de la salud del mundo clásico, encarnadas en las teorías hipocráticas y galénicas, pero supieron dar un matiz característico a la ciencia del medicamento y su desarrollo profesional ${ }^{15}$. Estudian el medicamento, con descripciones normalizadas, con reconocimiento de falsifícaciones, y con descripción de fórmulas. Y además, ¡surge por primera vez una profesión dedicada exclusivamente al medicamento, a su estudio, manipulación y dispensación, haciendo de su práctica un arte!; sin vínculos médicos como el diagnóstico y la prescripción.

Desde finales del siglo X, existía en todo el mundo árabe, incluido Al-Andalus, una clase farmacéutica, bien estructurada y científicamente preparada, al frente de las farmacias privadas y de hospitales, mientras que en el Occidente cristiano faltaban todavía dos siglos y medio para que medicina y farmacia se separasen mediante el edicto de la carta Magna de Federico II.

El auge de la farmacia profesional en el Islam Medieval, como entidad separada de la medicina, siguió los mismos patrones de desarrollo que otras disciplinas del campo de la salud. En una primera época, al no existir legislación administrativa al respecto, no podía prohibirse que el farmacéutico diera una diagnóstico, o que el médico elaborase y dispensara medicamentos a sus pacientes. Comenzarían a poblarse las zonas rurales y las ciudades con charlatanes y otros profesionales sin formación, dedicados a la elaboración de medicamentos. Ello llevaría a los gobernantes a regular el establecimiento de farmacias, en las que se elaboraban y vendían medicamentos, tanto de hospitales como privadas.

15. Obras generales sobre la Historia de la Farmacia son: ANDRÉS TURRIÓN, M.L. (1992): «La Farmacia en el Islam» en Imágenes de la Farmacia española a través del tiempo. Burgos, pp. 17-22; BOUSSEL, P. (1949): Histoire lllustrée de la Pharmacie, Paris; COWEN, D.; HELFAND. W.H. (1990): Pharmacy: an illustrated history. Vol. I, New York; FOLCH JOU, G. (1972): Historia de la Farmacia, Madrid; FOLCH JOU, G. (1986): Historia General de la Farmacia, Madrid; GRACIA GUILLÉN, D. y Otros. (1987): Historia del medicamento, Barcelona; VILLANUEVA, C. (1958): «La Farmacia árabe y su ambiente histórico», Miscelánea de Estudios Árahes y Hebraicos, Vol. VII, pp. 29-83. 
El establecimiento de la primera farmacia propiamente dicha, ha sido discutido por varios autores. La mayoría la sitúan en la ciudad de Bagdad, alrededor del 750-754. Fuentes documentales atestiguan la instauración de este tipo de establecimientos en Bagdad durante el reinado del califa al-Mahdī (775-785). Además de la manipulación de drogas, también realizaban análisis de orina mediante métodos organolépticos.

El desarrollo de estas farmacias en Al-Andalus fue más tardío, ya que comienzan a aparecer a finales del siglo X. Ya durante el reinado de Al-Hakām II (961976) consta la existencia de una farmacia, llamada Khizanat al-Adwiyah, en una habitación de palacio, y a cuyo frente estaba el farmacéutico Ahmad ibn Yunis. Tenía a su cargo doce jóvenes, trabajando en la preparación de remedios, muchos de los cuales eran dispensados gratuitamente a los pobres.

No obstante, podemos aseverar que en Al-Andalus participaban distintos profesionales dentro del ámbito farmacéutico: charlatanes, alquimistas, sandalinis, atarines, recolectores, farmacéuticos de hospitales, muhtasib, etc.

La figura del charlatán árabe constituye una curiosa intromisión en el campo sanitario. Muchos de ellos alcanzaron grandes fortunas con remedios o panaceas universales. El fraude, el engaño y la decepción que estos charlatanes árabes provocaron fue perseguido y denunciado tanto por las autoridades como por diversos autores.

Los alquimistas ${ }^{16}$, al encuentro de su objetivo primordial: la búsqueda de la panacea universal o quinta esencia, y la transmutación de los metales al llamado oro filosófico. Los continuos intentos y experimentos permitieron enriquecer la materia médica y darían paso a las primeras investigaciones químicas. Las creencias galénicas sobre la toxicidad de los remedios minerales, hizo que su aplicación fuera de carácter tópico y con grandes precauciones.

El desarrollo de la Farmacia en el Islam va unido a sus profesionales propiamente dichos: los saydalānīs, los attarines, y los recolectores de plantas medicinales y minerales. El constante enriquecimiento con nuevos medicamentos y la aparición de nuevos métodos de elaboración favoreció la aparición de un estamento independiente.

Junto al progreso de la ciencia farmacológica, fueron apareciendo las primeras farmacias, que fueron perfeccionándose con los años. El sacerdote farmacéutico del siglo XIII, Cohen el Atthar en su Manual de la Oficina de Farmacia dirigido a los farmacéuticos, precisa los modos de reconocimiento de drogas, conservación,

16. Sobre los alquimistas: BERQUE, J. (1967): «Hellénisme et Alchimistes arabes», en L Ámbivalence dans la culture arabe, París, pp. 111-115; ESTEVA DE SAGRERA, J. (1991): La química sagrada De la alquimia a la química en el siglo XVII. Madrid.; ESTEVA DE SAGRERA, J. (1992): «La Alquimia» en Imágenes de la Farmacia espanola a través del tiempo. Burgos, pp. 23-27.; FOLCH JOU, G. (1978): «Medicamentos empleados por los árabes y su posible influencia en la introducción de la Química en la Farmacia», Asclepio, Vol. XXX, pp. 177-186; GANZENMULLER, W. (1974): L'Alchimie au Moyen Age Verviers; GARCÍA FONT, J. (1976): Historia de la Alquimia en España, Madrid. 
medidas, preparación, así como los deberes y derechos del mismo. Demuestra lo vinculada que esta profesión está a la medicina, enumerando las cualidades que deben ser requeridas para practicar el arte farmacéutico: honestidad, virtuosidad, temor de Dios y de los hombres,... Constituyen los capítulos I y XXIII un verdadero código deontológico de la profesión.

Una de las grandes contribuciones de los sandalinis fue la introducción de formas de administración desconocidas en el mundo occidental. El farmacéutico árabe ya no se limitaba a realizar operaciones simples como la pulverización, mezcla y disolución. Entre las nuevas formas aparecen jarabes, conservas, confecciones, julepes y electuarios. En cada una de ellas había un ingrediente dulce, la miel o el azúcar, lo que contradecía la antigua creencia clásica de que sólo aquellos medicamentos amargos tenían una eficaz acción terapéutica.

También novedad en el campo farmacéutico, sería la incorporación de nuevos recipientes para la conservación de medicamentos. Utilizarían materiales diversos, adoptando formas variadas. Conocemos cajas de madera, vasos de oro y plata para confecciones, botes de porcelana,... Los nuevos métodos de manufactura de la cerámica, importados desde China, supondrían la introducción del esmaltado de recipientes. Entre éstos botes destaca especialmente uno, conocido con el nombre de albarelo: vasija cilíndrica de boca ancha y algo estrecha en su centro. Estos recipientes fueron utilizados durante los siglos siguientes, tanto en las farmacias privadas como en la de hospitales, y constituyen hoy en día todo un símbolo de nuestra profesión.

Para la elaboración de medicamentos hicieron uso de un sistema de pesas estrictamente medicinal, botes esmaltados, alambiques, morteros, espátulas, tamices,...

Existían tres clases de apotecarios, aparecidos inicialmente en Oriente, y posteriormente en Al-Andalus ${ }^{17}$. El primero es el profesional formado científicamente, al que al-Biruni denominó al-Saydalānī (el farmacéutico), o al-natasi (el instruido). En el mundo cristiano fueron conocidos como sandalinis, proveniente de la droga sándalo, la cual fue introducida desde Oriente en la farmacopea árabe. Era una entidad profesional bien diferenciada del resto de las clases sanitarias, y consta su existencia a mediados del siglo VIII en Bagdad. Tenían su propia tienda de venta de drogas en la que vendían simples y compuestos según prescripciones médicas. También esta clase ejercía como farmacéutico jefe en los dispensarios de medicamentos que existían en los hospitales. A ellos debemos gran parte del auge y consideración de la Farmacia como arte.

Una curiosa anécdota de finales del siglo VIII, relata como la favorita del califa abásida Mahdī, de nombre Khiruzan, encargó a su doncella que llevara su orina

17. Sobre la profesión farmacéutica: HAMARNEH, S.M. (1962): "The rise of profesional Pharmacy in Islam», Medical History, Vol. 6, pp. 59-66; HAMARNEH, S.M. (1972): "A History of Arabic Pharmacy", Physis, Vol 14, pp. 5-54; HAMARNEH, S.M.(1973): Origins of f harmacyand Therapy in theNear East, Tokio;HAMARNEH, S. (1973): «Some aspects of medical practice and institutions in Medieval Islam». Episteme. Vol. 7, pp. 15-31. 
al médico para determinar su malestar. Sin embargo ésta, se la confió a un preparador de drogas, llamado Abu Koreich, quién en su análisis de la orina determinó el embarazo de la favorita.

Parece ser que los primeros farmacéuticos andalusíes que habían recibido una educación particular pertenecen a la primera mitad del siglo IX (unos cincuenta años más tarde de la aparición de la primera botica). La formación es consecuencia de la necesidad de otorgar a los profesionales, una responsabilidad ética y técnica por su acto profesional.

Conocemos algunos de los nombres andalusíes de estos profesionales. Abū Yahyā ibn Qāsim (s. XII), de Sevilla, que era jefe del laboratorio de sirupes y electuarios del palacio del rey almohade Abū Yūsuf al-Mansūr. Y Abū Ya'far ibn al-Gazāl, natural de Higueira (Almería), famoso por la preparación de la triaca. También consta que en la segunda mitad del siglo XII, el médico sevillano Avenzoar tenía una muy buena relación con este colectivo en los que confiaba plenamente como profesionales instruidos en el arte de elaborar medicamentos.

La segunda clase, y probablemente la más común, eran los llamados al-'attarin. Poseían un buen conocimiento de la materia médica y destacaban en la preparación de medicamentos: sirupes, electuarios, aceites, etc..., pero carecían de una formación científica. Su formación procedía exclusivamente de la práctica. Vendían toda clase de especies y de plantas medicinales, incluso entre ellos existía un grupo llamado sharābiyīn que vendían sirupes, aguas aromáticas y perfumes.

La tercera clase estaba formada por los recolectores de plantas medicinales y minerales. El fuerte comercio y la obtención de buenos beneficios por determinadas plantas, hizo que fuera común la adulteración. Para evitarlo se establecieron diversos métodos y ensayos de identificación.

Ya en la primera mitad del siglo, consta la existencia de la primera y segunda clase que hemos mencionado, ya que a los farmacéuticos cualificados (saydalān̄i) se les daba una autorización administrativa especial para abrir sus tiendas cerca de los campamentos militares, mientras que los attarin eran excluidos.

En ocasiones, algunos médicos recelosos de que sus prescripciones fueran elaboradas incorrectamente por los farmacéuticos, sobre todo por los no instruidos o attārīn, continuaron elaborando sus propios medicamentos o bien bajo su directa supervisión. Todavía en el siglo XII, había médicos que prescribían las recetas y elaboraban ellos mismos en sus farmacias.

También se ocuparon los instruidos de las boticas de hospitales o bimaristanes (Granada). La prescripción médica o receta era enviada a la farmacia del hospital desde otras secciones del mismo. Allí, el boticario elaboraba el medicamento. Existían grandes almacenes de drogas, ya que se llegaron a contabilizar más de 3.000 drogas diferentes, muchas de las cuales eran frecuentemente falsificadas con sucedáneos. 
Una de las prácticas más comunes era la elaboración de listas especiales denominadas alDustur al blmaristarı en las que se registraban aquellos simples y compuestos utilizados con una acción probada. Normalmente, en grandes hospitales, existía un pequeño jardín de plantas medicinales para consumo del propio hospital.

Junto a estos profesionales existían otros que realizaban su labor en otras instituciones sanitarias: en los baños y en los mercados.

Los denominados baños árabes o hamman fueron un factor importante en la cultura árabe, tanto desde el punto de vista sociológico como terapéutico ${ }^{18}$. Eran muy abundantes en todas las ciudades. La Córdoba de mediados del siglo X contaba con más de 300 baños públicos. La importancia terapéutica del baño radicaba en las cualidades propias de éste, sus sales, y en la temperatura. El mejor momento para el baño era después de un suave ejercicio y antes de las comidas. Era completado normalmente con masajes sobre la piel que previamente había sido lubricada con unguentos. La práctica del baño alcanzó gran popularidad, lo cual por otra parte era lógico, ya que los árabes, entre las ventajas del baño, contemplaban: la disolución de las flatulencias, la expulsión de humores superfluos, la eliminación del sudor, del picor y de la tiña, humectación del cuerpo, mitigación de dolores de gota y del catarro, etc... Por contra su toma excesiva tampoco era aconsejada ya que producía laxitud del cuerpo, falta de apetito, inapetencia sexual, etc...

El muhtasib, o inspector de mercados estaba obligado a inspeccionar las farmacias y los mercados, siendo auxiliado por los arifs (ayudantes). Realiza funciones de policía sanitaria, controlada por el gobierno, en ocasiones con demasiada rectitud. En los distintos tratados de hisbah ${ }^{19}$, quedan reflejados los cometidos que debían desarrollar, y las problemáticas con que se encontraban. Organizados desde los primeros días del Islam fueron desarrollados por la administración con el objeto primordial de cuidar la salud pública y la lucha contra el fraude. Entre los más curiosos destacan el Tratado de Ibn 'Abdūn, en el que se describe las funciones del muhtasib sevillano de comienzos del siglo XII, y un tratado publicado por un muhtasib de la Málaga de la primera mitad del siglo XII, llamado Muhammad al-Saqati. Contiene diversos capítulos referentes a la inspección de los mercados, de perfumerías ('attārūn), tiendas de drogas (sayādila), de fábricas de sirupes (sarābiyūn), visitas a médicos veterinarios, flebotomistas,... y los trucos empleados en la falsificación de estos artículos. Entre otros, cita como falsifican los gengibres con rizomas semejantes que se encuentran en las montañas de Al-

18. Sobre los baños y Ia higiene: VÁZQUEZ DE BENITO, M.C. (1984): Libro del cuidado de la salud durante las estaciones del año o Libro de Higiene. Edición, estudio y traducción. Salamanca.

19. Sobre los tratados de hisbah: GARCÍA GÓMEZ, E., LEVÍ PROVENCAL, E. (1981): Sevilla a comienzos del siglo XII, El Tratado de Ibn Ábdün, Sevilla. 
Andalus, y lo mismo con el nardo, la canela y la almáciga falsificada con una resina de la terebinto. También alude a la falsificación de determinadas formas farmacéuticas como la del electuario de anís.

\section{MEDICAMENTOS Y MATERIA MÉDICA ${ }^{20}$}

En cuanto a los medicamentos en sí, realizan grandes innovaciones. Aparecen nuevas formas farmacéuticas, técnicas y modos de preparación de medicamentos, nuevas aplicaciones terapéuticas, etc... Djuad inventa un looc y un jarabe. Yunes el Harrany crea un electuario llamado «Marist el Kébir». Se utilizan técnicas como la destilación, sublimación, cristalización y filtración. Abén Vaye inicia las aplicaciones terapéuticas del anís. Abderrahman ben Isaac estudia en profundidad los purgantes. Abén Samadjún adjudica interesantes efectos a la acedera, al acónito y al mirabólano. Utilizaron gran número de simples del reino vegetal, animal y mineral, cuya lista sería interminable nombrar ahora, pero como anécdota reseñar que algunos de estos han quedado incorporadas a los conocimientos de nuestro pueblo, que los practica hoy lo mismo que Ios andalusíes de hace mil años. En determinados ámbitos aún se siguen usando telarañas para taponar las heridas sangrantes, y el pepinillo del diablo, por la nariz, en las ictericias. Se da hierbabuena a los niños para que expulsen los áscaris, y ruda frita contra los dolores de vientre.

Los Medicamentos Compuestos se preparaban en una gran variedad de formas farmacéuticas, unas heredadas de la antigüedad clásica y otras de creación árabe. Se crearon los trociscos y la emulsión de almendras que llamaron «looc». El jarabe es también otro invento árabe preparado con azúcar, producto que sustituyó en parte a la miel. Los macerados o cocimientos de flores, raíces, hojas, semillas, cortezas y sumidades se hicieron también populares, y aún hoy se acostumbra en la medicina casera andaluza a dejar la flor de manzanilla u otros remedios de tipo vegetal en una vasija con agua, para tomarlos al día siguiente. Las aguas destila-

20. Sobre Materia Médica: BOUSSEL, P. (1949): Histoire Illustrée de la Pharmacie. París; BoUSSEL, P.; BONNEMAIN, H. (1977): Histoire de la Pharmacie. París; FOLCH JOU, G. (1972): Historia de la Farmacia. Madrid, pp. 107-127; FOLCH JOU, G. (1978): «Medicamentos empleados por los árabes y su posible infiuencia en la introducción de la Química en la Farmacian, Asclepio, Vol. XXX, pp. 177- 186; HAMARNEH, S .M. (1969): «Origins of Arabic Drug and Diet Therapy», Physis, Vol. 11, pp. 267-286; HAMARNEH, S.M. (1970): «Sources and Development of Arabic Medical Therapy and Pharmacology», Sudhoffs Archiv. Zeitschrift Fur WissenchaftsGeschichte, Vol. 54, pp. 30-48; HAMARNEH, S.M. (1972): «Development of Arabic Medical Therapy in the Tenth Centnry», Journal of the History of Medicine, Vol. 27, pp. 65-79; HAMARNEH, S.M. (1972): «Pharmacy in Medieval Islam and the History of Drug Addiction», Medical History, Vol. 16, pp. 226-237; HAMARNEH, S.M. (1976): «Arabic Glass Seals on Early Eighth-Century Containers for Materia Medica», Pharmacy in History. Vol . 18, Nº 3, pp. 95- 102; LEVEY, M. (1961); «Ibn Māsawaih and His Tratise on Simple Aromatic Substances: Studies in the History of Arabic Pharmacology II", Journal of History of Medicine. Vol. 16, pp. 394-410, LEVEY, M. (1963): «Ibn al-Wahshīya's <Book of Poisons>, Kitāb al-Sumūm: Studies in the History of Arabic Phannacology II», Journal of History of Medicine. Vol. 18, pp. 370-377. 
das y los aceites denominados bálsamos, que eran plantas medicinales en un vehículo oleoso. Utilizaron las píldoras, que platearon y doraron por vez primera creyendo que aumentaban sus propiedades. Utilizaron los supositorios, entre ellos los chyafs, magdaleones cuya forma dieron también a algunos colirios sólidos.

En cuanto a los compuestos más comunes citaremos la Triaca, muy usado especialmente en el Al-Andalus Califal, donde existía el cargo de preparador de la triaca, ostentado por farmacéuticos de prestigio. Destacaremos la miel rosada como calmante del sistema nervioso. El jarabe de moras para combatir la distensión intestinal producida por los higos. El jarabe de limón para calmar las excitaciones que se producen en el corazón por el uso del cilantro. El jugo de trébol mezclado con miel cicatriza las úlceras de los ojos.

En algunas patologías comunes utilizaron: contra la peste fumigaciones de alcanfor, sándalo, madera de áloes, triaca, mitridato y almizcle. Para la gota la «Margarita medicinal», que hubo de traducirse en 1593 para curar a Felipe II, a base de una planta que en árabe se llama «Alaz Manchuni», y que probablemente fue el lentisco, abundante en las laderas de Sierra Nevada. Contra la lepra tratamientos a base de mezcla de hierbas, entre éstas la mandrágora, así como el aceite de chaulmoogra incorporado por Avenzoar.

\section{CONCLUSIÓN}

Podemos decir que aunque la Farmacia árabe irá unida inevitablemente a la Medicina, al igual que hoy en día, supo adquirir una nueva identidad y supuso el nacimiento de algunos aspectos importantes de la profesión. Con ella nació la botica (Bagdad, último cuarto del siglo VIII), establecimiento donde se dispensaban las drogas y elaboraban medicamentos, que sería el germen de la actual oficina de farmacia o farmacia comunitaria. También nacerá la farmacia hospitalaria que abre una nueva vertiente en la profesión. Dan gran importancia a la higiene, a la alimentación, establecen fuertes inspecciones de los mercados; y en definitiva organizan un sistema sanitario bien estructurado.

La importación de fármacos exóticos, la expansión del comercio de medicamentos, las nuevas formas de administración, los nuevos envases de cerámica esmaltada para la conservación, entre ellos el famoso albarelo, las fórmulas complejas, los aromatizantes, la mayor dependencia de la química,... todo ello en su conjunto habla a las claras del gran proceso de cambio que experimentó la farmacia. Había ya un especialista, el farmacéutico, que conocía las drogas y donde encontrarlas, sabía identificarlas y distinguir las auténticas de las falsificaciones, conocía sus indicaciones terapéuticas, y lo más importante, había hecho del proceso de elaboración de medicamentos un arte. 